\title{
A Critical Review on Non-Load Bearing Wall Based on Different Materials
}

\author{
Dr. Jayeshkumar Pitroda ${ }^{1}$, Krunalkumar A. Bhut ${ }^{2}$, Hardik A. Bhimani ${ }^{3}$, \\ Sagar N. Chhayani ${ }^{4}$, Uday R. Bhatu ${ }^{5}$, Nirav D. Chauhan ${ }^{6}$ \\ ${ }^{1}$ Assistant Professor, Civil Engineering Department, B.V.M. Engineering College, \\ VallabhVidyanagar-Gujarat-India \\ ${ }^{2,3,4,5,6}$ Student of final year B.E., Civil Engineering Department, B.V.M Engineering College, \\ Vallabh Vidyanagar-Gujarat-India
}

\begin{abstract}
The main objective of this study is to develop the integrated framework that can be useful in analyzing factors affecting the non-load bearing wall construction. Non-load bearing walls are important part of any structure. Construction of this type of wall depends on self-weight, structural design, easiness in transportation and construction. Main characteristics of non-load bearing wall are depending on types of materials and its specification so, study or analysis of different materials which are suitable for the constructions of non-load bearing wall are necessary. The study of the most significant key indicators like strength, cost, weight, flexibility, availability, sound proofing, life span, thermal conductivity etc. of non-load bearing wall. This analytic study aimed to investigate the adequacy and advantages of non-load bearing wall based on different materials like Concrete Hollow Blocks containing Recycled Window Glass, Polymer Precast Panel, Fly Ash Brick, Autoclaved Aerated Concrete (AAC)Block, Acotec Panel, Traditional Stone, Paper Fiber Reinforced Foam Concrete (PFRFC) Material, Clay Bricks, Glass Fiber Reinforced Gypsum (GFRG) Panel.
\end{abstract}

Keywords: Non-Load Bearing Wall, Construction Materials, Partition Wall

\section{INTRODUCTION}

There are two types of walls in a house non-load bearing and load bearing. Non-bearing walls divide the internal space into rooms but carry no load. The role of Load bearing wall as dividers, but they also carry the load of the structure. These serving as important structural elements, bearing walls transfer the weight of the roof and upper floors to the foundation. All outer walls are bearing walls. They support the roof at the ends of the joists. The interior bearing walls support the floors and dead loads. They support the joists at midpoint. A non-load bearing wall is a wall that does not carry any gravity loads from the building, hence doesn't accept any weight besides its own. A partition wall is a non-load-bearing wall that divides any interior space. Partition walls include static walls built onto the existing framed walls in the space or moveable features that slide on rails or roll on casters. A structural frame of reinforced concrete or steel can support the loads of the floors and roof, and also of the non-load bearing walls. The outer walls then perform all the 'enclosure' functions. Each wall panel also transmits its own weight and resists wind and seismic loads, but only those that act on the panel itself.

Partition walls are useful for changing the arrangement and functionality of a space. Following ways partition walls can be used:

1. Constructing separate workspaces in a large office space.

2. Providing a quieter reading or tutoring space in a classroom or library.

3. Separating a common bedroom into two distinct areas for additional privacy.

4. Partitioning an apartment to separate the sleeping and living areas.

5. Using pre-fabricated walls and screens to hide storage space.

Partition wall may be purpose-designed and constructed or may be flexible systems, and can combine openings, windows, doors, ducting, pipe work, plugs, wiring, skirting and so on. Frame constructions 
may include insulation to prevent the passage of sound or fire between adjacent spaces. It is important therefore that the top and bottom of the wall are appropriately sealed against the floor and ceiling, and where a raised floor or suspended ceiling is present, it is important to consider the possible for 'flanking' through the voids above and below.

Internal wall partitions, also known as office partitioning, is usually made of plasterboard or varieties of glass. Hardened glass is a common option, as is low-iron glass.

\section{LiterATURE REVIEW}

The following are the previous research review based on Non-Load Bearing wall based on Different Materials.

\subsection{Autoclaved Aerated Concrete (Aac) Block}

Habib et al (2015) found that in this research, generation method of hydrogen gas was used for the aeration process. In this gasification method, a finely powdered aluminum powder was added to the slurry of Ordinary Portland cement with different percentages such as $0.05 \%, 0.1 \%, 0.15 \%, 0.2 \%$, and $0.25 \%$. To determine the effect of aluminum powder on the final product properties, some test has been conducted such as density, water absorption and compressive strength test. However, it was observed that the concrete having $0.15 \%$ aluminum powder contributes in the strength gaining process of aerated concrete. (1)

Miao et al (2015) found that the reinforced concrete shear wall in self-thermal insulating system of AAC block can avoid the internal surface dew condensation on walls by pasting thermal-insulating places and plastering thermal-insulating mortar materials. The construction treatment of pasting heatthermal plates outside concrete shear wall and smearing thermal-insulating mortar can avoid the inner surface condensation trouble of AAC block self-thermal insulation system wall. (12)

Rathi et al (2015) found that Compressive strength of AAC blocks is comparatively more than traditional clay brick. These are suitable for walls in RCC framed building. Utilization of fly ash leads to the reduction in the cement consumption in the product which results in reduction of greenhouse gases. Density of AAC block is $1 / 3$ that of traditional clay brick and there is no more change in wet condition. It helps in reducing dead load of structure. Cost of construction reduces by maximum up to $20 \%$ as reduction of dead load of wall on beam makes comparatively lighter members. As both side face of AAC block wall are plane, thickness of plaster is very less, and so there is substantial reduction up to $50 \%$ in requirement of cement and sand for plaster work. AAC is manufactured from common and abundant natural raw materials, therefore it is extremely resource-efficient and eco friendly. (22)

Saiyed et al (2015) found that only natural materials are used in the process of manufacturing AAC block. This process produces no pollutants or by-products. AAC is totally free of poisonous or injurious substances. AAC a very eco-friendly building material and system. In the process manufacturing Low energy is required, low raw material consumption, ease of use in construction, and better indoor air quality. (8)

\subsection{Clay Brick}

Kaushik et al (2007) found that modulus of elasticity of masonry is found to vary between 250 and 1100 times the prism strength of masonry. An average value of 550 times the prism strength is proposed in the present study. The compressive strength of masonry was found to increase with the compressive strength of bricks and mortar. The trend was more prominent in case of masonry constructed with weaker mortar. Therefore, using a mortar grade of higher strength than required may not always produce high-strength masonry. Masonry with lime mortar was found to undergo about $50 \%$ more compressive deformation than that constructed using mortar without lime, while the reduction in compressive strength was only about $13 \%$ when lime mortar was used. Therefore, adding lime to mortar is a recommended practice in masonry construction. (9)

More et al (2014) found that the clay burnt bricks manufactured with fly ash and rice husk ash had similar appearance when compared to the conventional clay bricks. The clay bricks having fly ash as an admixture showed the best performance, having a compressive strength of about $23 \%$ greater than that of conventional bricks. The percentage of water absorption for these bricks was found to be more than that of conventional bricks but still within the prescribed maximum limit as per Indian Standards. (Maximum allowable water absorption as per Indian Standards is 20\%) Hence fly ash can be used as an admixture with clay bricks. (3) 


\subsection{Fly Ash Brick Wall}

Kumar et al (2014) found that Structure of the bricks was found to be compact, homogeneous and free from any defects like holes, lumps etc. as compared to normal bricks. The average absorbed moisture content of clay bricks and fly ash bricks are found to be $11.93 \%$ and $9.77 \%$ respectively. Thus there is net $18.10 \%$ decrease in moisture absorbed for fly ash bricks as a part to clay bricks. (18)

Mistry et al (2011) found that as compare to conventional brick masonry prism compressive strength it is between $13.75 \mathrm{~kg} / \mathrm{cm}^{2}$ to $121.80 \mathrm{~kg} / \mathrm{cm}^{2}$ at 28 days strength. While FaL-G brick prism strength is $88.83 \mathrm{~kg} / \mathrm{cm}^{2}$ for cement mortar $(1: 6)$ and $85.05 \mathrm{~kg} / \mathrm{cm}^{2}$ for fly ash mortar (1:6) just in 14 days. It can be increased up to $135 \mathrm{~kg} / \mathrm{cm}^{2}$ to $145 \mathrm{~kg} / \mathrm{cm}^{2}$ at 28 days. According to case study the fly ash bricks with conventional masonry work have $28 \%$ saving in cost with common red brick and conventional masonry work. The masonry work with new technology Rattrap bond in fly ash bricks have 33\% saving in cost as compared to common bricks. (20)

Patel et al (2013) found that increase the percentage of the fiber in brick the compressive strength of the brick is increase and the water absorption of the brick is decrease. In this experimental work $1 \%$ fiber addition in the brick gives the maximum strength $5.86 \mathrm{~N} / \mathrm{mm}^{2}$ after 21 days. Increase the percentage of glass fiber strength of the brick is increase but the cost of the brick is also increase. The maximum higher strength brick cost is 11.4 Rs. per number of brick. Cost of this brick is high but if we use this brick mix for the replace as PCC (Plain Cement Concrete, BBCC (Brick Bat Cement Concrete), RCC (Reinforced Cement Concrete) at plinth level and also it can be used in compressive element so the cost of the PCC, BBCC and RCC is decreases. (15)

Sumathi et al (2014-2015) found that the brick specimen of size $230 \mathrm{~mm} \times 110 \mathrm{~mm} \times 90 \mathrm{~mm}$ were cast for different mix percentage of Fly ash (15 to 50\%), Gypsum (2\%), Lime (5 to 30\%) and Quarry dust (45 to 55\%). However, the specimens have been tested for seven mix proportions. The mechanical properties such as compressive strength were studied for different mix proportions, at different curing ages. From the results it was inferred that, among the seven proportions the maximum optimized compressive strength is obtained for optimal mix percentage of Flyash-15\% Lime-30\% Gypsum-2\% Quarry dust-53\% as $7.91 \mathrm{~N} / \mathrm{mm}^{2}$. (23)

\subsection{Glass Fiber Reinforced Gypsum(GFRG) Panel}

Janardhana et al (2015) found that axial load carrying capacity of unfilled GFRG wall panels, of various widths when subjected to eccentric loads, is estimated using numerical analysis. The lateral load carrying capacity of panels is also estimated. A basic procedure has been suggested for assessing in plane flexural strength of concrete filled wall panels. For a given force demand, reinforcement required for a concrete filled GFRG wall panels can be obtained using interaction diagram that has been developed. Using simple approach, the capacity of unfilled panels under shear load is estimated. It is also established by comparing the results of finite element buckling analysis with the available experimental results, that failure of the GFRG wall panel does not occur. Due to buckling, on account of in-plane axial and shear loads, as the critical loads are much higher than the actual capacities. (13)

Liu et al (2010) found that a new GFRG wall, named M-GFRG wall, which intended to erect small high-rise residential. Considerations on M-GFRG walls show that they can erect building fast like GFRG wall in prefabricated method. The following conclusions of its lateral deformation feature are derived from the elastic FEM analysis. The lateral stiffness of M-GFRG wall is a little smaller than that of reinforcing concrete shear wall, but it still is enough rigid for the small high-rise building. The elastic analysis shows that the M-GFRG wall is possible to be used in the small high-rise residential. But it still needs more theory analysis and experiment research for engineer application. (25)

Manjummekudiyil et al found that GFRG Panels are light weight building material which can be used as walls and roof slab. Phospho-Gypsum, which is bi-product of fertilizer industry, can be effectively used in the production of panel. Compressive strength of GFRG Panel was obtained as $1.25 \mathrm{~N} / \mathrm{mm}^{2}$. Water absorption value is obtained as $1.225 \%$. (6)

Shukla et al (2016) found that the lengthwise reinforcement has no significant effect on shear response of concrete filled GFRG panels. Therefore, panels with starter bars as reinforcement could be used for which shear failure controls the design. Axial load has a similar effect on the shear strength of the walls. As a result, the type -one connection (starter bar) is acceptable for GFRG wall building if failure is due to shear strength of the wall. However, these conclusions are only valid for 
shear prevailing wall panels. They are not valid for the walls with flexural deformations, for which the continuity of reinforcement is substantial. (2)

\subsection{Paper Fiber Reinforced Foam Concrete(PFRFC) Panel}

Fadila et al (2008) found that waste paper is suitable to reinforce foam concrete in term of flexural strength and noise absorption, but it not appropriate for foam concrete caused by increasing the density. The best percentage of Paper Fiber is $10 \%$ of mix volume, because without any admixtures it could achieve the strength almost similar to the strength of 20\% PFRFC that have been added by admixtures. Paper Fiber has very high ability in absorption of water. However, it absorption ability give the other advantages in absorbing noise. (16)

Mohd et al observed that various sampling and testing of specimen and identified collected data have been discussed with a purpose to carry objective attainment of this research of study. Marginally the paper fiber provides a lot of benefit to increase the strength of concrete mixture, as new material for the concrete or cement composite to go along with economical construction material, and other excellence competent to be exploited accurately. (7)

Rai et al (2014) found that Fiber is added in concrete to improve ductility and its post-cracking loadcarrying capacity. The most important effect of fiber reinforcement in concrete is not to strength but also for flexural toughness of the material. Fiber reinforced concrete is generally made with a high cement content and low w/c ratio. Plain concrete fails abruptly once the deflection corresponding to the ultimate flexural strength is exceeded, on the other hand, fiber-reinforced concrete continues to withstand considerable loads even at deflections significantly in additional of the fracture deflection of the plain concrete.(4)

Zakaria et al (2015) found that it is concluded that the natural fiber has potential to be used in composites for any different purpose. Various aspects of fiber reinforced composites have already been investigated and achieved the best result reported by previous researchers. Natural fiber when used as an aggregate in cement composite production can contribute in making the material and as a result: the structure enhancing the environment in a friendly manner. Recycling or such wastes as a sustainable construction material comes into view as a feasible solution not only to solve pollution crisis but also as cost-effective solution for designing of green buildings concept. (14)

\subsection{Polymer Pre-Cast Panel}

Mackechnie et al found that by using the concrete itself as the insulating material, we are improving the use of the material. This would also save the use of other insulating mediums that are not ideal in terms of energy efficiency and prevent the full thermal mass of concrete being utilized. These panels have been designed using recycled materials or by-products from other industries. The concept is therefore to build from our waste instead of putting it into landfills. Portland cement production is a high energy process that could be replaced by using inorganic polymer binder instead of Portland cement. This would prevent a large value of $\mathrm{CO}_{2}$ emission to be released. (11)

Rajaieh et al (2013) observed that to respond the residual requirement and with regard to population growth trend, economic condition and reaching to consistent development, construction industrializing is one of the effective solutions. We will be encounter a noticeable reduction in cost of wall operation, building dead load, environmental pollution, energy consumption in produce and building beneficiary and operation speed increment and effective infrastructure and ease of mechanical and electrical implementation by utilizing of these panels in operation of building internal and external partition walls. (10)

\subsection{Recycled Glass Wall}

Bhandari et al (2013) found that compressive strength of OPC mortar for 1, 3, 7 and 28 days for standard sand was observed to be greater than that of local sand (Wainganga sand) for control mix. The use of waste glass aggregate usually reduces the water demand. With the addition of waste glass aggregate, density of mortar increases. Water absorbed is less by cubes containing waste glass aggregate as compared to control mix cubes. (5)

Gautam et al (2012) found that use of waste glass as fine aggregate replacement, the strength is found in 28 days, to slightly increase up to $20 \%$ replacement level. Marginal decrease in strength is observed at 30 to $40 \%$ replacement level of waste glass with fine aggregate. (19) 
Krishnamurthy et al (2013)found that the thermal conductivity increased with the increasing in percentage of crushed recycle glass. Crushed recycle glass has a good and excellent potential in construction industry not only in reducing energy costs and effects of global warming by recycle the glass but to provide good insulation in concrete especially for use in tropical country. (17)

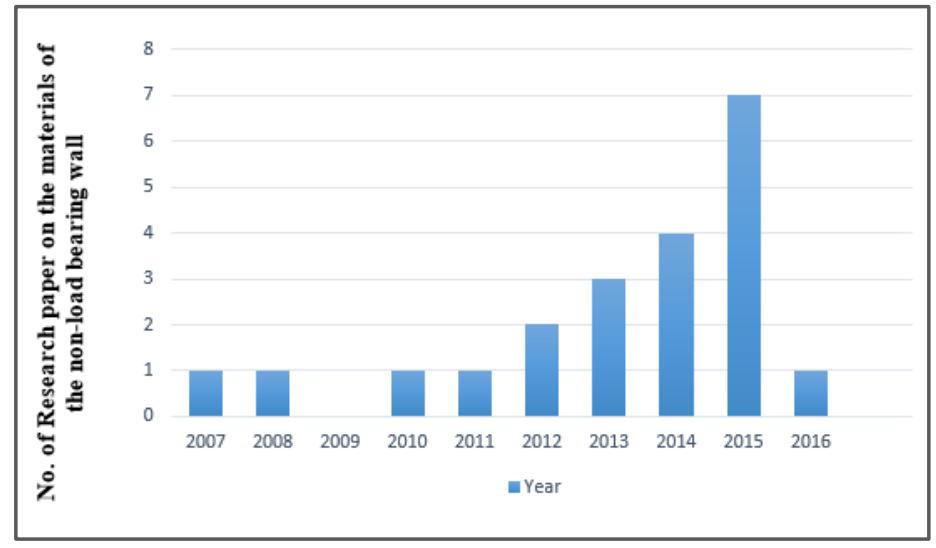

Figure1. Historical Development in the Area of Non-Load Bearing wall based on Different Materials used in

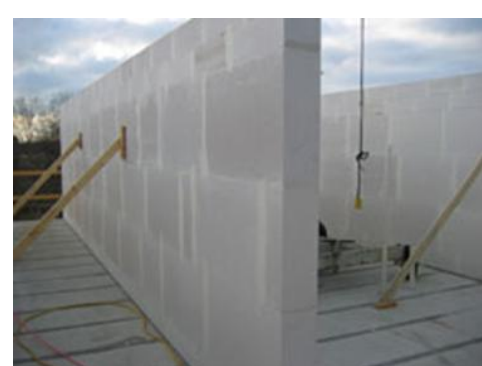

Autoclaved Aerated Concrete (AAC) Block

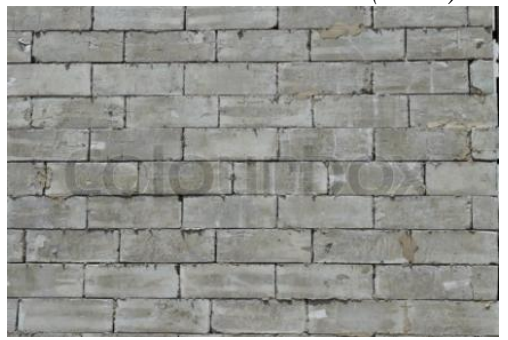

Fly Ash Brick Wall

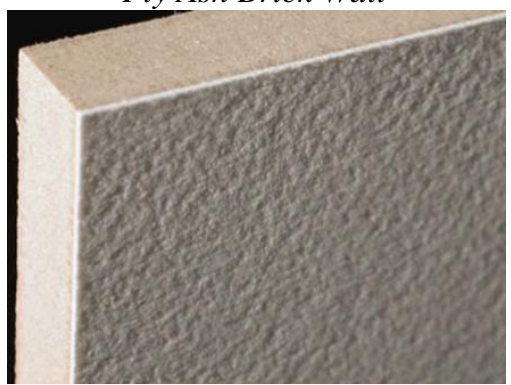

Paper Fiber Reinforced Foam Concrete (PFRFC)

Panel

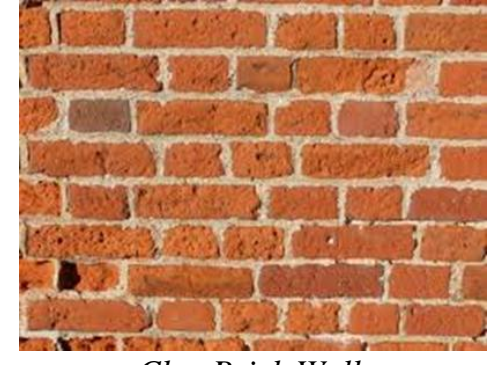

Clay Brick Wall

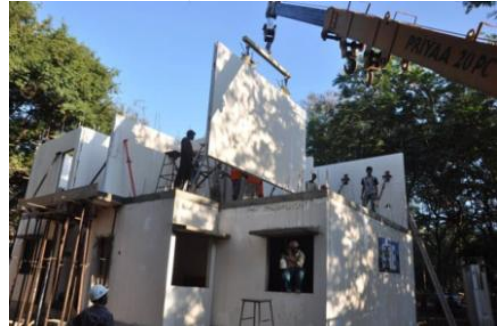

Glass Fiber Reinforced Gypsum (GFRG) Panel

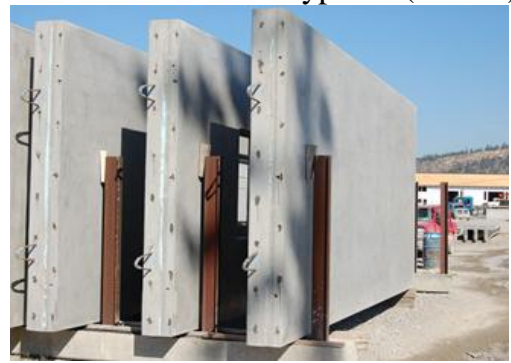

Polymer Pre-Cast Panel

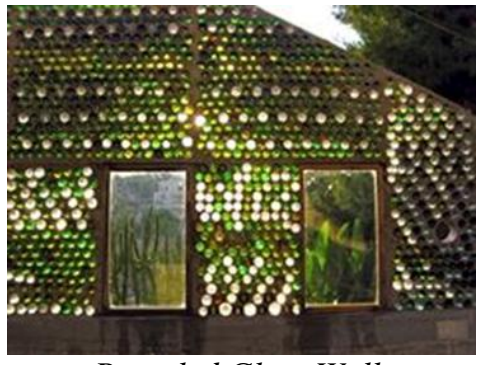

Recycled Glass Wall

Figure2. Different Materials used in Non-Load Bearing wall 


\section{CONCLUSIONS}

Based in Literature Review the following conclusions are drawn:

1. Utilization of fly ash leads to the reduction in the cement consumption in the product which results in reduction of greenhouse gases. Cost of construction reduces by maximum up to $20 \%$ as reduction of dead load of wall on beam makes comparatively lighter members. (22)

2. Only natural materials are used in the process of manufacturing AAC block. This process produces no pollutants or by-products. AAC is totally free of poisonous or injurious substances. AAC a very eco-friendly building material and system. (8)

3. The compressive strength of masonry was found to increase with the compressive strength of bricks and mortar. Masonry with lime mortar was found to undergo about 50\% more compressive deformation than that constructed using mortar without lime. (9)

4. The clay bricks having fly ash as an admixture showed the best performance, having a compressive strength of about $23 \%$ greater than that of conventional bricks. (3)

5. The average absorbed moisture content of clay bricks and fly ash bricks is found to be $11.93 \%$ and $9.77 \%$ respectively. Thus there is net $18.10 \%$ decrease in moisture absorbed for fly ash bricks as a part to clay bricks. (18)

6. As compare to conventional brick masonry prism compressive strength it is between $13.75 \mathrm{~kg} / \mathrm{cm}^{2}$ to $121.80 \mathrm{~kg} / \mathrm{cm}^{2}$ at 28 days strength. While FaL-G brick prism strength is $88.83 \mathrm{~kg} / \mathrm{cm}^{2}$ for cement mortar (1:6) and $85.05 \mathrm{~kg} / \mathrm{cm}^{2}$ for fly ash mortar (1:6) just in 14 days. It can be increased up to $135 \mathrm{~kg} / \mathrm{cm}^{2}$ to $145 \mathrm{~kg} / \mathrm{cm}^{2}$ at 28 days. (20)

7. With increase the percentage of the fiber in brick the compressive strength of the brick is increase and the water absorption of the brick is decrease. Increase the percentage of glass fiber strength of the brick is increase but the cost of the brick is also increase. (15)

8. The lateral stiffness of M-GFRG wall is a little smaller than that of reinforcing concrete shear wall, but it still is enough rigid for the small high-rise building. The elastic analysis shows that the M-GFRG wall is possible to be used in the small high-rise residential. (25)

9. Compressive strength of GFRG Panel was obtained as $1.25 \mathrm{~N} / \mathrm{mm}^{2}$. Water absorption value is obtained as $1.225 \%$. (6)

10. The best percentage of Paper Fiber is $10 \%$ of mix volume, because without any admixtures it could achieve the strength almost similar to the strength of $20 \%$ PFRFC that have been added by admixtures. (16)

11. Fiber is added in concrete to improve ductility and its post-cracking load-carrying capacity. The most important effect of fiber reinforcement in concrete is not to strength but also for flexural toughness of the material. Fiber reinforced concrete is generally made with a high cement content and low $\mathrm{w} / \mathrm{c}$ ratio. (4)

12. The use of waste glass aggregate usually reduces the water demand. With the addition of waste glass aggregate, density of mortar increases. Water absorbed is less by cubes containing waste glass aggregate as compared to control mix cubes. (5)

\section{ACKNOWLEDGMENT}

The Authors thankfully acknowledge to Dr. C. L. Patel, Chairman, Charutar Vidya Mandal, and Er. V. M. Patel, Hon. Jt. Secretary, Charutar Vidya Mandal, Prof. (Dr.) Indrajit Patel, Principal, B.V.M. Engineering College, Dr. L. B. Zala, Head and Professor, Civil Engineering Department, Prof. J. J. Bhavsar, Associate Professor, Civil Engineering Department, B.V.M. Engineering College, Vallabh Vidyanagar, Gujarat, India for their motivations and infrastructural support to carry out this research.

\section{REFERENCES}

[1] AhsanHabib "Study on production of Aerated concrete block in Bangladesh" IJISET International Journal of Innovative Science, Engineering \& Technology, Vol. 2 Issue 3 | March 2015.

[2] AishwaryShukla "A Review of Research on Building System Using Glass Fiber Reinforced Gypsum Wall Panels" International Research Journal of Engineering and Technology (IRJET) Volume: 03 Issue: 02, Feb-2016 
[3] AkshaySatish More "Assessment of suitability of Fly Ash and Rice Husk Ash burnt clay bricks" International Journal of Scientific and Research Publications, Volume 4, Issue 7, July 2014. ISSN 2250-3153.

[4] Amit Rai "Applications and Properties of Fibre Reinforced Concrete" Int. Journal of Engineering Research and Applications. ISSN: 2248-9622, Vol. 4, Issue 5(Version 1), May 2014.

[5] Bhandari. P.S "Use of waste glass in cement mortar" International Journal of Civil and Structural Engineering. Volume 3, No 4, ISSN 0976 - 4399, 2013.

[6] Eldhose M Manjummekudiyil "Study of GFRG panel and its strengthening" International Journal of Civil and Structural Engineering Research Vol. 2, Issue 2, pp: (161-165), Month: October 2014 - March 2015

[7] FahrizalZulkarnain, Mohd. Zailan Suleiman RahyanFadila "the potential usage paper fiber reinforced foam concrete (PFRFC) wall paneling system as an idea building material" International Journal of Advanced Research (2016), Volume 4, Issue 2, 139-148.

[8] Farhana M. Saiyed "Aerated Autoclaved Concrete (AAC) Blocks: Novel Material for Construction Industry" International Journal of Advanced Research in Engineering, Science \& Management. ISSN: 2394-I766.

[9] Hemant B. Kaushik "Construction and Implementation of Non-Load Bearing Walls by Using Polymer-precast Panels with Plaster Matrix and Comparing Them with Existence Systems" Department of Civil Engineering, Indian Institute of Technology Kanpur, Kanpur 208 016, India.

[10] HoseinRajaieh, Yaser Mandi Sanam, M. HadiRafiee, SeyedMojtabaBagha "Construction and Implementation of Non-Load Bearing Walls by Using Polymer-precast Panels with Plaster Matrix and Comparing Them with Existence Systems" International Journal of Construction Engineering and Management 2013, 2(1): 1-7.

[11] James R. Mackechnie "New Insulating Precast Concrete Panels" SB07 New Zealand, Paper number: 065.

[12] Jikui Miao "Research on Self-Thermal Insulation Wall Construction Technology of Autoclaved Aerated Concrete Block" 5th International Conference on Civil Engineering and Transportation (ICCET 2015)

[13] MagantiJanardhana "Studies on the Behavior of Glass Fibre Reinforced Gypsum Wall Panels".

[14] Noor ZawatiZakaria "Turning Natural Fibre Reinforced Cement Composite as Innovative Alternative Sustainable Construction Material: A Review Paper" International Journal of Advanced Engineering, Management and Science (IJAEMS) [Vol-1, Issue-8, Nov- 2015] ISSN: 2454-1311.

[15] Nutan C. Patel "Fly Ash Brick: Glass Fiber the Innovative Concept for Getting Higher Strength Brick" International Journal of Innovative Research in Science, Engineering and Technology Vol. 2, Issue 3, March 2013.

[16] RahyanFadila "Paper Fiber Reinforced Foam Concrete Wall Panelling System" 2nd International Conference on Built Environment in Developing Countries (ICBEDC 2008).

[17] RengaRao Krishnamurthy, Juvinia Augustine Zujip "Thermal Conductivity and Microstructure of Concrete Using Recycle Glass as a Fine Aggregate Replacement" International Journal of Emerging Technology and Advanced Engineering Volume 3, Issue 8, August 2013.

[18] Rinku Kumar "An Experimental Study on Properties of Fly Ash Bricks" International Journal of Research in Aeronautical and Mechanical Engineering, ISSN (ONLINE): 2321-3051.

[19] S.P. Gautam "Use of glass wastes as fine aggregate in Concrete" J. Acad. Indus. Res. Vol. 1(6) November 2012

[20] Sameer Mistry "Fly Ash Bricks Masonry: An Experimental Study" National Conference on Recent Trends in Engineering \& Technology.

[21] Shweta O. Rathi "Cost Effectiveness of Using AAC Blocks for Building Construction in Residential Building and Public Buildings" IJRET: International Journal of Research in Engineering and Technology ISSN: 2319-1163, ISSN: 2321-7308.

[22] Shweta O. Rathi, P.V. Khandve "AAC Block - A New Eco-friendly Material for Construction" International Journal of Advance Engineering and Research Development Volume 2, Issue 4, April -2015. 
[23] Sumathi "Compressive Strength of Fly Ash Brick with Addition of Lime, Gypsum and Quarry Dust” International Journal of Chem Tech Research CODEN (USA): IJCRGG ISSN: 0974-4290, Vol.7, No.01, pp 28-36, 2014-2015.

[24] Tomas UcolGaniron "Recycled Window Glass for Non-Load Bearing Walls" International Journal of Innovation, Management and Technology, Vol. 3, No. 6, December 2012.

[25] Zhengyong Liu "Elastic Lateral Features of a New Glass Fibre Reinforced Gypsum Wall" International Journal of Civil, Environmental, structural, Construction and Architectural Engineering Vol.: 4, No: 3, 2010.

\section{AUTHORS' BIOGRAPHY}

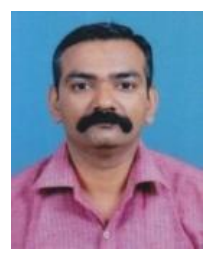

Dr. Jayeshkumar Pitroda, received his Bachelor of Engineering Degree in Civil Engineering from Birla Vishwakarma MahavidyalayaEngineering College, Sardar Patel University in 2000. In 2009 he received his master's degree in Construction Engineering and Management form Birla Vishwakarma Mahavidyalaya Sardar Patel University. In 2015 he received his Doctor of Philosophy (Ph.D.) Degree in Civil Engineering from Sardar Patel University. He joined Birla Vishwakarma Mahavidyalaya Engineering College as a faculty in 2009, where he is Assistant Professor of Civil Engineering Department with a total experience of 16 years in the field of Research, Designing and Education. He is guiding M.E. / M.Tech (Construction Engineering and Management) thesis work in the field of Civil / Construction Engineering. He has published many papers in National / International Conferences and International Journals. He has published seven Research Books in the field of Civil Engineering, Rural Road Construction, National Highways Construction, Utilization of Industrial Waste, Fly Ash Bricks, Construction Engineering and Management, Eco-friendly Construction.

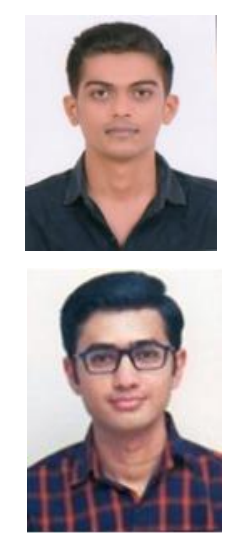

Krunalkumar A. Bhut, is student of final year, B.E. Civil Engineering.Study in BVM Engineering College, Vallabh Vidyanagar, Gujarat, India.

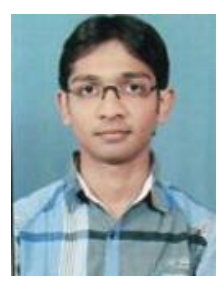

Hardik A. Bhimani, is student of final year, B.E. Civil Engineering.Study in BVM Engineering College, Vallabh Vidyanagar, Gujarat, India.

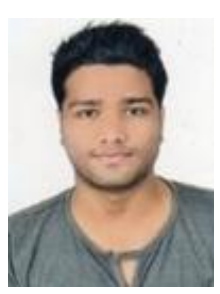

Sagar N. Chhayani is student of final year, B.E. Civil Engineering. Study in BVM Engineering College, Vallabh Vidyanagar, Gujarat, India.

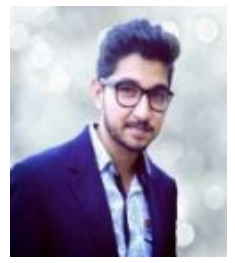

Uday R. Bhatu is student of final year, B.E. Civil Engineering. Study in BVM Engineering College, Vallabh Vidyanagar, Gujarat, India. 